\title{
Capital culturel, innovation sociale et gestion de l'innovation technique
}

Synthèse du groupe de travail $n^{\circ} 1$ - animé par Mike Singleton

Hélène Pagezy

\section{OpenEdition}

Journals

Édition électronique

URL : http://journals.openedition.org/apad/3833

ISSN : 1950-6929

Éditeur

LIT Verlag

Édition imprimée

Date de publication : 1 décembre 1992

\section{Référence électronique}

Hélène Pagezy, «Capital culturel, innovation sociale et gestion de l'innovation technique », Bulletin de I'APAD [En ligne], 4 | 1992, mis en ligne le 26 juin 2008, consulté le 07 septembre 2020. URL : http:// journals.openedition.org/apad/3833

Ce document a été généré automatiquement le 7 septembre 2020.

Bulletin de l'APAD 


\title{
Capital culturel, innovation sociale et gestion de l'innovation technique
}

\author{
Synthèse du groupe de travail $n^{\circ} 1$ - animé par Mike Singleton
}

\section{Hélène Pagezy}

$1 \quad$ L'atelier s'est structuré autour de trois projets implantés en Afrique de l'Ouest. Les exemples présentés au cours de cette séance ont cherché à démonter les mécanismes par lesquels facteurs sociaux, culturels, religieux et économiques entraient en interaction dans les projets de développement, lieux privilégiés d'innovation sociale, selon une logique propre à chacun d'eux.

2 Un projet d'architecture en pays lobi (M. Spini) a cherché à concilier les impératifs économiques aux besoins sociaux, culturels et religieux exprimés par les vieux et les jeunes. Sa stratégie d'action a consisté à repérer les innovations spontanées et à les intégrer dans l'architecture traditionnelle. Il a été remarqué qu'un changement total de références (symboliques et religieuses par exemple) pouvait remettre en question une telle stratégie mais que néanmoins ce type de démarche avait sa place dans le créneau temporel que constitue une période de transition sans rupture majeure. L'atelier a souligné le principe selon lequel la population devait être informée de tout projet la concernant, et qu'elle avait le droit d'accepter ou de refuser les projets qu'on lui propose.

3 Un exemple d'intensification des périmètres agricoles en pays Mossi (P-J. Laurent) a montré comment la religion protestante s'est insérée dans la vie villageoise par le biais des pasteurs. L'image de dynamisme produite par ces pasteurs, malgré celle d'ascétisme qui leur est associée, leur a permis de jouer le rôle de modèle auprès de la population et d'exercer ainsi leur prosélytisme : les pasteurs sont condamnés à réussir pour s'imposer. L'atelier a insisté sur la récupération des structures existantes et ses conséquences sociales: ainsi l'assemblée de Dieu est devenue assemblée de développement et a joué le rôle de contre-pouvoir politique.

Un troisième exemple construit autour d'un projet cotonnier a servi à comparer les formes associatives anciennes et actuelles dans la région Mali Sud (D. Jonckers). Il a été remarqué que les ONG avaient souvent pensé le monde traditionnel comme étant un 
lieu vide d'associations, parce qu'ils n'ont en vue que des associations à but lucratif et productif. Outre leur côté convivial, brueghelien, les sociétés secrètes traditionnelles peuvent être le siège de stratégies politiques et sociales, de résistance passive, véritables lignes de force des sociétés africaines. Il a été conclu que les assemblées villageoises modernes n'étaient pas obligées de tirer leurs racines des assemblées traditionnelles pour exister; les formes actuelles n'ont rien à voir avec les anciennes, car elles reposent sur des logiques économiques et sociales différentes. Enfin, il a été soulevé le problème du mythe associatif: les paysans ont-ils intérêt à s'associer? Leur logique n'est-elle pas plutôt de tirer parti d'un certain laisser-faire opportuniste? Les projets de développement ne répondent-ils pas à une logique de complicité, à travers laquelle asociaux, associables et associants trouvent des avantages. 